DOI 10.37882/2223-2982.2021.05-2.33

\title{
ТИПОЛОГИЯ СЛОВЕСНЫХ ПРОСОДИЙ РАЗНОСИСТЕМНЫХ ЯЗЫКОВ СКВОЗЬ ПРИЗМУ ИССЛЕДОВАНИЙ В РУСЛЕ ЛИНГВОКОНТАКТОЛОГИИ
}

\section{WORD-PROSODIC STRUCTURE OF TYPOLOGICALLY DIVERSE LANGUAGES THROUGH THE PRISM OF CONTACT LINGUISTICS}

\section{E. Uyutova}

Summary: The article discusses the problem of word prosody classification in typologically diverse languages. The author suggests that the results of the study on the interference phenomena in Korean English speech can be used for the typological analysis of Korean word prosody. The specifics of Korean word prosodic structure becomes more obviously highlighted in Korean English accented speech. In particular, the prosodic structure of an English word is replaced in Korean variant by unclear, indefinite "nativeKorean" type of prosody. The results of the study make doubtful the fact of existence of Korean word stress in terms of traditional Indo-European phonology (as an opposition of accented and unaccented syllables).

Keywords: language contacts theory, typological classification, English, East-Asian English varieties, interference, word prosody, word stress, tonal languages, lack of stress, vowel harmony, intensity, pitch.

\section{Введение}

$\mathrm{H}$ аучные исследования в области лингвоконтактологии пользуются неизменной популярностью как у отечественных, так и у зарубежных лингвистов с момента зарождения этой области языкознания во второй половине XX в. На современном этапе мы являемся свидетелями мощнейшего развития теории языковых контактов, что проявляется в многочисленных исследованиях, связанных с проблемами взаимодействия автохтонных языков с английским как языком глобального межкультурного общения [12]. Бесспорно революционным явилось положение, предложенное одним из основоположников лингвоконтактологии индийским лингвистом Б. Качру о том, что английский язык, став языком межкультурного общения, перестал принадлежать только его носителям [21]. Распространенность английского языка как средства общения по всему земному шару позволяет выделить и описать множество его региональных вариантов. В настоящее время региональные варианты выделяются как в отношении конкретных этнических групп (японский английский, корейский английский), так и в отношении определенных государств (китайский английский - применимое к мно-

\author{
Уютова Евгения Викторовна \\ К.филол.н., дочент, Академия гражданской защиты МЧС \\ России, г. Химки \\ uyutova_ev@mail.ru
}

Аннотация: В статье поднимается проблема типологической классификации разносистемных языков с точки зрения словесной просодии. Автор предлагает использовать результаты исследования явлений интерференции в английской речи носителей корейского языка для типологического анализа его словесной просодии. Сквозь призму иноязычного акцента специфика просодического устройства слова интерферирующего языка становится более явной. В частности, просодическая композиция слова английского языка в речи корейцев подменяется размытым, нечетким типом словесной просодии. Полученные результаты дают веские основания выразить сомнения относительно наличия в корейском слове словесного ударения, во всяком случае, в традиционном индоевропейском понимании этого термина как просодического противопоставления выделенного слога невыделенному.

Ключевые слова: теория языковых контактов, типологическая классификация, английский язык, восточно-азиатские варианты английского языка, интерференция, просодия слова, словесное ударение, тоновые языки, анакцентность, сингармонизм, интенсивность, ЧОТ.

гочисленным народностям Китая) и территорий (западноафриканский английский, восточноазиатский. английский). Все варианты обладают уникальной спецификой, проявляющейся на всех языковых уровнях в виде акцента (фонетического, грамматического, лексического). Рассуждая о значении исследований в русле лингвоконтактологии, следует отметить их непосредственную связь с практикой преподавания английского языка, а также с практикой перевода. Однако сквозь призму лингвоконтактологии, направленной на изучение особенностей английского языка неанглоязычных коммуникантов, часто ярко проявляются и специфичные черты контактирующих языков.

Цель исследования - проанализировать возможности применения результатов исследований в русле лингвоконтактологии для типологического анализа и классификации разносистемных языков в общей теории языка.

Научная гипотеза состоит в том, что результаты научных работ, исследующих явления интерференции в английской речи носителей различных языков мира, могут широко применяться в таких областях языковедения, как типология разносистемных языков. Данная гипотеза 
сформировалась в ходе работы автора данной статьи над исследованием просодических характеристик корейского варианта английского языка. Обширное теоретическое компаративное исследование просодических систем, контактирующих английского и корейского языков, а также данные, полученные в ходе аудитивного и электро-акустического анализа экспериментального материала (образцов английской речи носителей корейского языка), позволили сделать ряд предположений о природе словестной просодии корейского языка. Напомним, что до настоящего времени с точки зрения просодической типологии корейский язык чаще всего имел статус «изолированного», т.е. не был включен в существующие типологические классификации.

Актуальность рассматриваемого вопроса обусловлена целым рядом факторов. В области просодической фонологии к настоящему времени накоплен большой фактический материал, освещающий словесную просодию языков различных групп и семей. Однако следует отметить, что вопросы глобального типологического анализа фонологических систем морфологически дифференцированных и генетически разнотипных языков мира с позиций просодической фонологии мало исследованы. Типологическая проблематика, чрезвычайно популярная в отечественной и зарубежной лингвистике ещё последних декадах прошлого столетия, сегодня, на наш взгляд, лишена должного внимания со стороны исследователей. Между тем, столь актуальные в современное время межязыковые исследования в области языковой вариантологии и лингводидактики не могут и не должны, по нашему твёрдому убеждению, обходиться без обращения к типологическому материалу. Обращение к данным языковой типологии в работах о речевой просодии тем более актуально в свете развития современного подхода интегрального описания языка [15].

В ходе исследования использовалась комплексная методология, включающая теоретический анализ и синхронно-сопоставительный типологический анализ.

Теоретической базой исследования послужили основные положения теории языковых контактов, теории языковой интерференции, языковой типологии. Применительно к двухсложному и многосложному слову термин просодическое устройство, просодия слова традиционно понимается как устройство вокалической части слова, установление сложившихся в данном языке взаимоотношений вокалических частей слогов слова, формируемых основными физическими (акустическими) характеристиками речевого звучания (частотой основного тона, интенсивностью, длительностью.

Каждый язык имеет свой просодический «ключ» и свой, свойственный только ему тембр звучания. Просодическое устройство слова - своего рода «националь- ная одежда» типологически различных языков - определяет основную специфику речевых интонаций. Именно по этой специфике речь распознается как принадлежащая к языку определённой просодической типологии: например, речь на языке со слоговыми тонами, на языке со словесным ударением, на языке с преимущественно временной организацией слова, на языке сингармонического типа.

Нормативно-произносительные взаимоотношения слогов в слове в каждом языке свои, и они не могут быть нарушены без нарушения произносительной нормы данного языка. Наибольшие различия в принципе просодического устройства наблюдаются в типологически различных языках.

\section{Обзор ^итературы по вопросу типологии просодических систем}

В лингвистической литературе обычно называются и с разной степенью обоснованности доказательств рассматриваются пять типов (принципов) просодического устройства слова в языках мира:

1. языки со словесным ударением;

2. тональные или тоновые языки;

3. 3) языки с сингармоническим устройством слова;

4. языки с правилами временных отношений слогов в слове;

5. языки, совмещающие тоновое устройство слова с ударением.

Такая классификация предложена в работе М.К. Румянцева, посвященной исследованию просодии слова в типологически разных языках [13]. По мнению С.В. Кодзасова, исследовавшего вопросы типологии просодии в языках разной ареальной и генетической принадлежности, базовые просодические схемы, которые можно потенциально встретить в языках мира сводятся к четырем:

1. тональная структура;

2. сочетание тона и ударения, 3

3. динамическая структура;

4. анакцентность [8].

Наиболее развернутая классификация просодических систем предложена в фундаментальной работе В.Б.Касевича «Фонологические проблемы общего и восточного языкознания» [6, с. 181-186]. Данная классификация построена на основании использования трех бинарных признаков: А - релевантность/иррелевантность просодической характеристики каждого слога; В - релевантность/иррелевантность места ударения; С - релевантность/иррелевантность качества ударения. В соответствии с классификацией В.Б. Касевича, выделяющей семь классов языков, английский язык относится к VI классу языков, для которых релевантно только место ударения, т.е. позиция ударного слога в слове. Призна- 
ком самостоятельности, цельнооформленности английского слова является наличие в нём ударения преимущественно динамического (часто смешанного) типа.

\section{Обсужмение}

Перечисленным типологическим концепциям нельзя отказать в основательности и большой объяснительной силе, однако они ни в коей мере не могут быть признаны исчерпывающими. По-прежнему существуют многочисленные языки, факты словесной просодии которых недостаточно изучены. К таковым, в частности, относится корейский язык. Вопрос о просодическом соотношений слогов в корейском слове заинтересовал автора данной статьи в ходе диссертационного исследования, посвященного описанию вариантологических произносительных особенностей английской речи носителей корейского языка [14]. Исследование выполнялось на кафедре фонетики Института иностранных языков ДВГУ и носило прикладной характер; результаты планировалось использовать для создания комплексного пособия, знакомящего переводчиков с произносительной спецификой восточно-азиатских вариантов английского языка. Теоретическим основанием для исследования послужил сопоставительный анализ фонологических систем английского и корейского языков. Анализ проводился на разных фонологических уровнях: сегментном и супрасегментном. В ходе данного исследования остро встала проблема определения статуса корейского языка в просодической типологии. Ни в оной из имеющихся в лингвистической литературе классификаций просодических систем нет ссылки на факты корейского языка, которые иллюстрировали бы тот или иной тип (принцип) просодического устройства слова. Причиной тому является, безусловно, слабая изученность проблемы корейской словесной просодии. Кроме того, следует учитывать тот немаловажный факт, что в корейском языке на разных стадиях его эволюции существовали слоговые тоны и сингармонизм. В этом - уникальность словесной просодии корейского языка и, несомненно, сложность ее исследования.

«Романтическое» определение корейского языка как языка-«призрака» в просодической типологии ни в коей мере не может удовлетворить пытливого исследователя. Бытует довольно распространенное заблуждение, в том числе среди лингвистов, о том, что корейский язык является тональным. Следует сразу оговориться, что это не так. Современный корейский язык не принадлежит к числу тональных языков. Несмотря на то, что в литературе часто можно встретить упоминание о корейских тонах, их функционирование относят к раннему, средневековому состоянию языка. Учитывая, что корейский язык не является ни тональным, ни (в полной мере) сингармоническим, уместно ожидать для него релевантности такой фонологической характеристики как акцентность.
Отметим, что мнения лингвистов (как индоевропеистов, так и ориенталистов) в значительной степени противоречивы. В ходе собственного исследования мы убедились, что нередко об ударении в корейском языке делаются прямо противоположные заключения, что в значительной степени осложняет задачу систематизации теоретического материала. Неслучайно корейские лингвисты называют эту область исследований корейского языка «минным полем» (mine field) [20, с. 3].

В целом существует две различные точки зрения. Согласно первой из них, которой придерживается большинство авторов, современный корейский язык использует именно ударение как особое фонологическое средство на уровне слова. При этом выдвигаются различные предположения относительно природы ударения, его акустических коррелятах, позиции в слове [2; $10 ; 18 ; 22]$. Другая точка зрения объединяет авторов, ставящих под сомнение фонологичность словесного ударения в корейском языке [7; 13].

Резюмируя весь исследованный общетеоретический, методический, дискриптивно-описательный, экспериментальный материал по интересующему нас вопросу, мы пришли к ряду выводов, которые ни в коей мере не претендуют на императивность:

1. Нам представляется, что факты наличия сингармонизма на более ранних этапах развития корейского языка заслуживают пристального внимания при рассмотрении проблемы эволюции просодического устройства корейского слова. Несмотря на то, что в современном корейском языке сингармонизм носит остаточный характер, возможно, его функционирование оказало определенное влияние на особенности акцентной системы. Корейский язык агглютинативен; словоформа корейского языка - это единица, с грамматической точки зрения обладающая слабовыраженной внутренней цельностью, поскольку она состоит из относительно самостоятельных элементов - корня и связанных служебных слов или аффиксов, каждый из которых несет свою семантику и функцию. В описанных условиях возникает необходимость в особом фонетическом оформлении агглютинативных единиц, способствующих их цельности. Именно эту задачу в языках агглютинативного типа и выполняет такое фонологическое средство как сингармонизм [3; 17]. С точки зрения речепроизводства сингармонизм выполняет консолидирующую функцию, с точки зрения восприятия обеспечивает сегментацию текста на словоформы и их вероятностную идентификацию. Известно, что абсолютное большинство языков, в которых наличие ударения сомнительно - это сингармонические языки (тюркские, тунгусо-манчжурские и некоторые другие) [9]. Признается, что словесное 
ударение в этих языках, если оно и существует, играет вспомогательную роль, находится в состоянии компенсации с сингармонизмом, характеризуется слабой выраженностью, отсутствием смыслоразличительной функции.

2. При рассмотрении сложнейшего вопроса об отнесении конкретного языка (в нашем случае - корейского) к определенному просодическому типу приходит мысль о том, что, возможно, назрела необходимость кардинально изменить подход к исследованию просодии корейского слова. Рациональным мы находим подход к обсуждаемой проблеме Л.Г. Зубковой, которая предлагает начинать исследование словесного ударения «с факта установления наличия данной категории в исследуемом языке, что требует привлечения для анализа фразового материала» [4, с. 51]. Применительно к звуковой форме слова Л.Г. Зубковой разработаны так называемые принципы интегрального описания, предполагающие зависимость фонологической типологии слова от грамматического строя языка. Л.Г. Зубкова обосновывает грамматическую мотивированность словесной просодии языка, утверждая, что звуковая форма слова как структурированная целостность отражает 1) единство универсальных, групповых и индивидуальных свойств языка; 2) иерархический характер его уровневой структуры.

Данная позиция представляется обстоятельной. До недавнего времени ударение рассматривалось с разных точек зрения автономно - как свойство фонетического слова, как характеристика словоизменительной парадигмы, как компонент фразовой интонации. Л.Г. Зубкова обращает внимание исследователей на то, что ударение - есть в первую очередь словесная характеристика, а, следовательно, его свойства определяются свойствами самого слова в системе языка» [5, с.129]. Из этого следует, что при выявлении наличия, природы и функций словесного ударения в конкретном языке необходимо учитывать семиотический статус слова и его положение в системе языковых единиц относительно единиц более высокого ранга (предложений), относительно единиц того же ранга (слов), относительно единиц более низкого ранга (морфем). При этом важным является сам тип языка, определяющий - в соответствии с его положением на шкале лексичности/грамматичности - соотношение значащих единиц друг с другом и их характер (степень сложности и постоянства морфемного строения словоформы).

Функционирование просодических средств (в частности, словесной просодии) выявляет единство языка через взаимокомпенсаторную связь между планом содержания и планом выражения, между парадигматикой и синтагматикой [4, с.77-78]. Чем проще значащая единица (в данном случае слово) в синтагматическом плане, тем больше значений она может иметь и тем актуальнее ее парадигматическое различение с помощью средств просодии. Так, например, английский язык, в котором на современном этапе действует тенденция к «лексикализации» (морфологическая неизменяемость слова, использование служебных слов и порядка слов в предложении как средств выражения грамматических отношений, конверсия), на уровне слова использует ударение как особое фонологическое средство, обладающее высокой степенью функциональной нагруженности (конститутивная, выделительная, дистинктивная функции английского ударения).

Напротив, чем сложнее синтагматическое строение значащей единицы, тем проще ее семантическая парадигма, тем вероятнее однозначность, и тогда необходимость в дополнительных просодических средствах либо ограничивается, либо вовсе отпадает [4]. Так, корейский язык представляет собой язык «грамматического» типа с весьма развитой и сложной морфологической структурой слова, обилием самых разнообразных грамматических форм. Словообразующие и формообразующие средства корейского языка «внешне» и «внутренне» гораздо самостоятельнее, чем в других языках (не только флективных, но и многих агглютинативных); он не «соединяются», не «спаиваются» с корнями, а только следуют за ними, причем границы, как правило, очень отчетливы. С большой степенью уверенности можно предположить, что перечисленные строевые особенности корейского языка неслучайным образом коррелируют с просодическим устройством корейского слова.

3) Изучение словесной просодии корейского языка представляется возможным с привлечением опыта, наработанного лингвистами в сопоставительных экспериментально-фонетических исследованиях $[1 ; 14 ; 19 ; 22]$. Несмотря на то, что целью упомянутых научных работ чаще всего является выявление фактов интерференции на супрасегментном уровне, могут быть получены результаты, способствующие более глубокому пониманию природы просодических явлений в сопоставляемых языках. Опыт нашего исследования особенностей акцентно-ритмической структуры английской речи носителей корейского языка позволил нам получить ряд интересных наблюдений. В частности, в ходе слухового, аудиторского и инструментального анализа английской речи корейцев были выявлены множественные нарушения супрасегментного характера, связанные с некорректной реализацией словесного ударения. Было установлено, что специфика просодического устройства слова в корейском языке оказывает интерферирующее влияние на акцентно-ритмическую организацию английской 
речи носителей корейского языка. Следствием этого влияния, например, является создание избыточного ударения в слове, а иногда - акцентное выделение каждого слога и «чеканное» произнесение слова в целом. Просодическая композиция слова английского языка, характеризующаяся в норме выраженным контрастом ударных и безударных слогов с характерной количественной и качественной редукцией безударных гласных, в речи корейских дикторов подменялась слабоконтрастным, размытым, специфически корейским типом словесной просодии. Данное заключение подтверждается результатами осциллографического и спектрального анализа изолированных слов и слов в составе фразы английского языка в реализации корейских дикторов. Специфика просодических взаимоотношений слогов в слове характеризуется незначительными различиями по длительности, отсутствием контраста по интенсивности и чОТ. Спектральные различия между гласными ударных и неударных слогов в словах английского языка в реализации корейских дикторов также не столь отчетливы, как в эталонном варианте. Характер перечисленных нарушений настолько специфичен, что в ходе слухового анализа аудиторам было зачастую трудно определить, какой из слогов английского слова в корейской реализации является выделенным.

\section{Зак^ючение}

На данный момент автор статьи склонен солидаризироваться с мнением тех отечественных и зарубежных лингвистов, которые в результате своих исследований приходят к убеждению, что в типологическом плане корейский язык может быть отнесен к акцентным языкам лишь с большой степенью условности $[2 ; 7 ; 11 ; 13 ; 16$; 20]. Собственный исследовательский опыт также дает нам веские основания выразить сомнения относительно наличия в корейском слове словесного ударения как просодического противопоставления одного (выделенного) слога другому (невыделенному). Возможно, применительно к корейскому языку корректнее говорить не об ударении (поскольку, строго говоря, этот термин подходит только к тем языкам, в которых отмечается сильный просодический контраст между ударным и безударным слогами, как, например, в языках типа английского, русского, польского и им подобных), а о некоем произносительном просодическом ранжире слогов в слове. При этом нельзя сбрасывать со счетов еще один важный фактор, особенно часто упоминающийся в работах корейских лингвистов по просодии, а именно фактор «тяжести» слога. Просодический «вес» слога в слове в корейском языке определяется не только по его вокалической части, но также и по консонантной. Но в этом случае уместнее говорить не о просодическом, а, скорее, о сегментно-просодическом устройстве слова, поскольку тот или иной просодический ранжир слогов в слове создается не только вокалическим звучанием, но и консонантным [2; 13].

В процессе изучения проблемы словесной просодии в корейском языке нам часто приходила мысль о том, что описать данное уникальное явление с использованием существующей в индоевропеистике традиционной терминологии - задача чрезвычайно непростая. Очевидно, что решение вопросов, связанных с местом корейского языка в просодической типологии, невозможно без участия в нем ориенталистов, так как индоевропеисты свое слово, кажется, уже сказали. Иных причин такого застоя В типологических исследованиях просодии корейского языка, на наш взгляд, нет. Неслучайно апелляция к восточно-азиатским языкам стала в общем языкознании обычным делом, когда материалы разноструктурных языков приходят в противоречие с традиционными теориями.

\section{ЛИТЕРАТУРА}

1. Бондаренко Л.П. Английский язык в странах Юго-Восточной Азии: Произносительные варианты. Корейский английский // Культурно-языковые контакты: сб. науч. трудов. Владивосток: Изд-во Дальневост.Ун-та, 1999. Вып. 2.С.3-12.

2. Бен Енг Сук. Просодическая организация фонетического слова и синтагмы в русском и корейском языка: Дис. ... канд. филол. наук. М., 2000. 187 с.

3. Золхоев И.В. Фонология и морфонология агглютинативных языков. Новосибирск, 1980. 142 с.

4. Зубкова Л.Г. Отражение лексичности/грамматичности языка в супрасегментной организации значащих единиц // IV Международная конференция по языкам Дальнего Востока, Юго-Восточной Азии и Западной Африки: сб. докладов. М.: МГУ, ИСАА, 1997. Ч.1. С.77-87.

5. Зубкова Л.Г. От типологической детерминанты языка и потребностей системы к специфике звукового строя // III Международный симпозиум МАПРЯЛ «Фонетика в системе языка». Тезисы докладов. М.: Изд-во РУдН. 2002. С. 38-40.

6. Касевич В.Б Фонологические проблемы общего и восточного языкознания. М.: Наука, 1983. 295 с.

7. Касевич В.Б. 0 просодике слова в корейском языке // Вестник Центра корейского языка и культуры / Под ред. А.Г. Васильева. С-Пб. 2003. Вып.5-6. С.17-29.

8. Кодзасов С.В. Типология просодии слова и данные дагестанских языков // Языкознание: Теория и эксперимент. Сб. статей. М.: МГУ, 2002. - С. $336-351$.

9. Логинова И.М. Типологическая характеристика слова и построение лингво-дидактической модели обучения // Языкознание: Теория и эксперимент.: Сб. статей. М.: МГУ, 2002. С.351-369.

10. Мазур Ю.Н. Корейский язык // Языки мира. М.: Изд-во «Индрик», 1997. С.361-398. 
11. Пак Су Бин. Фонетические особенности имен числительных в русской речи корейцев // Вестник СпбГУ. Спб., 1997. - Сер.2. Вып.4, № 23. - С. 105-108.

12. Прошина 3.Г. Межкультурная коммуникация: английский язык и культура народов Восточной Азии: учебное пособие для вузов / 3.Г. Прошина. - 2-е изд., испр. и доп. - Москва: Издательство Юрайт, 2020. - 400 с. - (Высшее образование).

13. Румянцев М.К. 0 просодии слова в типологически разных языках // VII Международная конференция по языкам Дальнего Востока, Юго-Восточной Азии и Западной Африки: сб. докладов. М.: МГУ, ИСАА, 2003. - Ч.ІІ. - С.98-108.

14. Уютова Е.В. Слого-ритмическая структура английской речи носителей корейского языка: Дис. ... канд. филол. наук. Владивосток, 2004. 263 с.

15. Хромов С.С. Семиотическая сущность интонации // Фонетика в системе языка: Сб. статей. М.: Изд-во РУДН, 2002. - Вып. 3.Ч.2. - С.148-153.

16. Чой Сун Ми. Сопоставление слоговых структур ккорейского и русского языков. М.: МГУ, 1996. - 9 с. - Деп. в ИНИОН РАН12.12.96, 52138.

17. Щербак А.М. Сравнительная фонетика тюркских языков. - Л. 1970. 204.с.

18. Athanasopoulou A., Vogel I. Emergence of word prosody in Korean [Электронный ресурс] // Proceedings of the International Conference of Experimental Linguistics ExLing 2016, 1-2 July 2016, Saint Petersburg. Pp. 10-15. URL: https://www.researchgate.net/profile/Angeliki_Athanasopoulou/ publication/307512379 (Дата обращения: 25.12.2020)

19. Ingram J.C., Park S-G. Cross-language vowel perception and production by Japanese and Korean learners of English [Электронный ресурс] // Јournal of Phonetics. Vol.25. No 3, July 1997. P. 343-370. URL: https://www.sciencedirect.com/science/article/abs/pii/S0095447097900486 (Дата обращения: 14.01.2021)

20. Jung Ye-Jee. Acoustic analysis of English lexical stress produced by Korean, Japanese and Taiwanese-Chinese speakers [Электронный pecyрc] // Phonetics and speech sciences. Vol.10. No. 1, March 2018, P. 15-22. URL: http://www.researchgate.net/publication/1324623039 (Дата обращения: 07.12.2020)

21. Kachru B.B. Englishization and contact linguistics // World Englishes. 1994. Vol.13, No. 2, P. 135-154.

22. Park S. Errors of English stress by Korean speakers// English Language and Literature Teaching. 2004. Vol. 10. № 3, P. 177-190.

(с) Уютова Евгения Викторовна (uyutova_ev@mail.ru).

Журнал «Современная наука: актуальные проблемы теории и практики»

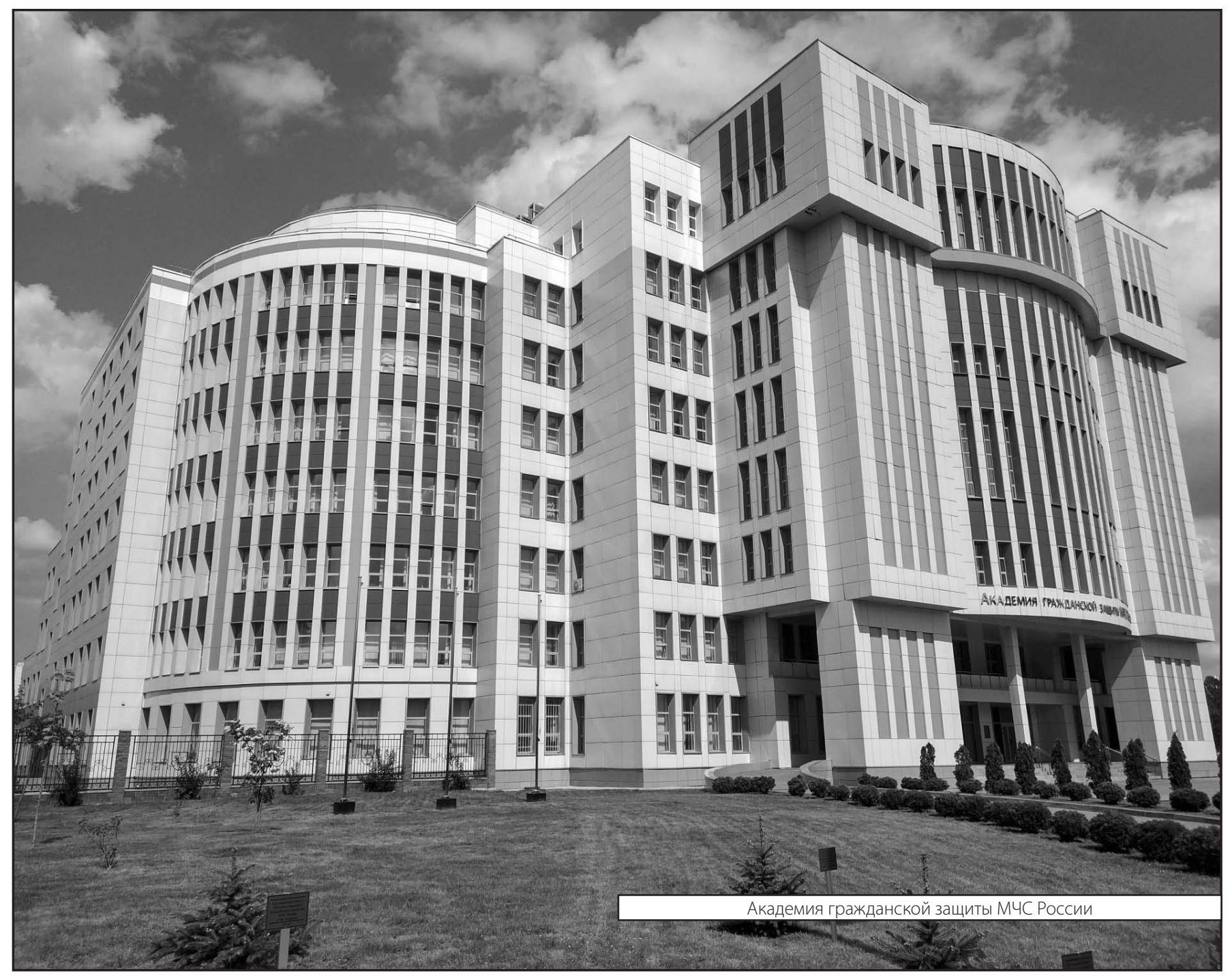

